\title{
Simultaneous Teaching of L1 and L2 Literacy to Young Iranian Learners: A Threat or A Treat?
}

\author{
Newsha Ahmadi, Roya Khoii, Hediyeh Taghadosian \\ Islamic Azad University, North Tehran Branch \\ Iran
}

\begin{abstract}
Despite the growing number of bilingual schools in Iran, the effect of bilingual education on the Persian literacy of young learners is subject to controversial debates among scholars. Some Iranian Persian teachers in bilingual schools hold that simultaneous teaching of the literacy of the L1 and L2 (first and second languages) has a negative impact on the efficiency of L1 literacy teaching. This research attempts to explore the potential impact of simultaneous literacy teaching of LI and L2 on the Persian literacy of first graders who lacked both Persian and English literacy at the outset of the study in a bilingual school. For this purpose the mastery of Persian literacy of 22 first graders in a bilingual school was compared to their counterparts in a monolingual school in two short and long term periods. Three read-aloud and three dictation tests were administered to two groups to compare their reading fluency, reading accuracy and dictation accuracy. The results indicated no difference in the mastery of $\mathrm{Ll}$ literacy between the two groups in the short term period, but an obvious superiority of the bilinguals in long term in mastering the reading fluency of their L1.
\end{abstract}

\section{Introduction}

The importance of English as an international language and lingua franca, as well as its essential role in higher education, has made many people all over the world to seek learning English in faster and more efficient ways in order to be able to communicate with the globalized world. During the past 20 years with the widespread use of social networks, internet and satellites in Iran, there appeared a widespread awareness among the parents regarding the importance of providing bilingual education for their children especially from younger ages. This specific need has led to a mushroom growth of private bilingual primary schools. These mushrooms come in different colors and shapes and standards, each following a different framework. It should be noted that the six year period of primary schooling in Iran is compulsory and free. The Persian Curriculum, syllabus and textbooks are originated, published and distributed by the ministry of Education. Moreover, all schools (public, private, monolingual or bilingual) nationwide are obliged to use the preplanned Persian Curriculum, Syllabus and textbooks. Contrary to the Persian curriculum which is unified nationwide, there is no standardized preplanned English curriculum and textbook to follow in bilingual schools. In spite of many differences between monolingual and bilingual schools, what is shared among the policy makers of these schools is that mastering L1 (Persian) literacy in first grade is of utmost importance and is set as the educational priority.

Despite the growing number of bilingual primary schools in Iran, the effect of bilingual education on the Persian literacy of young learners is unknown. A group of Persian teachers in bilingual Iranian schools hold that English literacy learning has, in fact, a negative impact on the students' progress in Persian literacy.

These teachers believe that simultaneous learning of Persian and English literacy is a real challenge for first graders studying at bilingual schools, and they strongly hold that for a more efficient learning procedure, teaching L2 literacy should be postponed to the second year of primary school to give the first graders ample opportunity to concentrate on the mastery of mother tongue literacy for one whole academic year in their first year at school. These groups of teachers justify their claim by presenting writing samples which indicate the challenge their learners are exposed to and its confusion effect.

Writing samples reported by these teachers show a high frequency of three typical phenomena namely mirror writing, mingled writing and wrong direction writing. Although mirror writing (backward writing in which the letters appear in reverse order) happens in monolingual schools as 
well, apparently it has a higher frequency in the case of bilingual first graders. This high frequency of occurrence is also true for wrong direction writing in both L1 and L2 writing samples collected at the bilingual school. The third interesting manifestation of the challenge is the mingled Persian English manipulation of the graphemes to represent phonemes. To illustrate, the Persian word "badbadak" (meaning kite) was reported to be written as $* K$ بادباد" in which the final /k/ sound which was supposed to be written with the Persian grapheme (ك) was written with (k), or the other young learner had written Bardiya (his name) as *Bardi $L$ in his English class handout.

Since L1 literacy is at the core of learning all other subjects at Iranian schools, especially at the first year of the presence of the students at primary school, it should be checked if simultaneous learning of L1 and L2 Literacy will lead to any negative or decelerating impact in the overall L1 literacy of the young learners. Obviously, if learning the literacy of a second language simultaneously with the literacy of the first language has any negative, harmful or slowing impact on L1 literacy of young learners or puts them in a confusing challenge, the problem needs to be dealt with. Given the controversial results of similar studies in this regard, this research was an attempt to explore these potential effects on the Persian literacy of young Iranian learners at the first grade of a bilingual primary school in Tehran.

\section{Theoretical Framework}

Until 1960, it was believed that students who are bilingual must have been at a disadvantage compared to the monolingual students. Barac\&Bialystoke [1] reported many early researchers' claims that the number of languages children learn, whether through "natural exposure or educational intervention", hinders their progress and has negative consequences. This is while there is an ample body of research which reports the benefits of bilingual and multilingual education (Bialystoke et al. [2], Menken [3], Woolfolk [4]). Different studies which compared bilingual students with monolingual peers have mentioned different advantages for the bilinguals namely in their cognitive and linguistic development, in concept formation, in metalinguistic awareness and in divergent and creative thinking (Caldas [5], Bialystoke [6], Diaz [7]).

Literacy teaching and learning is one of the inseparable crucial elements in bilingual educational systems. Literacy is defined in a variety of different ways by different scholars. For example Cameron [8] states that "Literacy skills include being able to read and write different sorts of texts for different purposes", and Hamers and Blanc [9] hold that "from an educational perspective, literacy can be viewed as a communication skill which involves a written mode of verbal transmission (reading and writing) employed by literate societies for effective functioning". What these definitions share is that reading and writing is seen as the basic components of literacy.

Obviously, when children start their first grade at primary school, they "know much more about oral language of their L1 than about written language" (Christie [10]). The first graders proficiency in oral language enhances his/her ability in learning to read and write, in other words, children who learn literacy in mother tongue, have taken the necessary steps to learn literacy in advance. Comparatively, the process is more problematic for those who learn literacy in a language other than their L1. Children at bilingual schools are exposed to "two literacies", and "Literacy itself changes with languages and contexts". If the two languages have different scripts (as it is the case with Persian and English), it doubles the amount the child needs to learn in order to decode basic text" (Bialystok [3]).

Gudschinsky [11], Ramírez [12] and Tsai,,et.al [13] along with many other scholars hold that L1 literacy and L2 reading skills promote L2 literacy. In spite of this census among the majority of the educators on the positive impact of the L1 literacy learning on proficient mastery of L2 literacy, there is no general agreement on the timing of this instruction. A group of educators believe that L2 literacy Instruction should be postponed to the time when the young learners have successfully mastered the alphabetic, orthographic, and phonemic awareness necessary for literacy learning in their L1. This is while in an outstanding number of Iranian bilingual schools, the first year of primary school is devoted to simultaneous teaching of L1 and L2 literacy.

The majority of first grade teachers and parents in Iran strongly believe the first and most important educational achievement of the first graders to be mastering L1 literacy and as Bialystok [8] holds parents would not want to do anything to risk their children's ability in learning to read i.e. if parents assume that having two languages will hinder or slow down the first graders L1 literacy mastery, they would definitely keep their children monolingual.

A number of studies have addressed the issue of the impact of L2 literacy on the L1 literacy. For example Hussein [14] addressed the effect of learning English (L2) on learning to read and spell connected texts in Arabic (L1). The bilingual and monolingual students who participated in this study were assessed for their reading and spelling accuracy. The results showed that the bilingual (Arabic-English) students out-performed their monolingual (Arabic) counterparts on both the oral reading and spelling accuracy. It was concluded that learning English has a positive effect on students' oral reading accuracy and spelling accuracy in Arabic.

In another recent study, Berens, Kovelman and Petitto [15] also investigated the efficiency to learn 
reading in two languages simultaneously or sequentially. In Simultaneous dual-language group, children were taught two languages within the same developmental period, while in Sequential dual-language group, students were taught one language, followed gradually by the other. Further they were compared to matched monolingual English-only children in single-language English schools. Bilinguals were tested in both languages which were English and Spanish, and monolingual children were tested in English using standardized reading and language tasks. One of the findings of this research indicated that, "children from Englishonly homes in dual language learning contexts performed equally well, or better than, children from monolingual English-only homes in singlelanguage learning contexts" [18]. Likewise, AL Dohon [16] investigated the effect of L2 learning (English) on L1 (Arabic) reading aloud and vocabulary skill among primary school students in UAE, and he reported the privilege of bilingual young learners who participated in his study compared to their monolingual counterparts leading the researcher to conclude that L2 has a positive impact on the L1 reading skill and vocabulary learning. Marsh [17] and Verhoeven [18] also reported a similar positive enhancing impact of L2 instruction on the reading abilities of Chinese and Turkish learners of English.

Nevertheless, in spite of the studies conducted in this regard (a few of which were presented here) and the results of the positive impact of L2 on L1, still there exist a widespread census among many first grade Persian teachers that simultaneous teaching of Persian and English literacy in bilingual primary schools will have a negative impact on the effectiveness of their L1 literacy teaching procedure. These teachers, the majority of whom have had the chance to teach in monolingual as well as the bilingual schools, claim that both based on their experience and their teacher intuition, that teaching the literacy system of two languages with different orthographic systems should not be carried out in the same academic year. This study was an attempt to investigate the truth-value of this claim.

\section{Methodology}

In the following sections, the research questions, instruments, participants and the procedure of the study will be explained.

\subsection{Research Questions}

In order to see whether there exists a significant difference between the level of mastery of Persian language literacy of first graders in monolingual and bilingual primary schools two research questions were formed:

a. Does simultaneous literacy teaching of

Persian and English affect first graders'
Persian literacy in bilingual schools in short term?

b. Does simultaneous literacy teaching of Persian and English affect first graders' Persian literacy in bilingual schools in long term?

\subsection{Participants}

The participants of this study were 44 sevenyear-old male primary school first graders studying at a bilingual (Persian-English), and a monolingual (Persian) primary school located in the same school district in Tehran. All participants were from monolingual Persian-speaking homes, and were raised in Iran. At the outset of the study the teachers of both classes in both schools were asked to mark out the students who were able either to read or write Persian and/or English to make sure that all the participants were illiterate both in L1 and L2 at the beginning. Moreover, in order to reduce the impact of socioeconomic variables only the students whose parents had university degrees were included in the study.

The experimental group included 22 first graders from a bilingual school and the other 22 participants at the monolingual school were taken as the control group. The students in both schools received instruction in Persian literacy for 400 hours, over 32 weeks of one academic year. This was while the students in the bilingual school received an extra 400 hours of English literacy instruction over the same period, in addition to their Persian literacy instruction.

\subsection{Instruments}

In order to assess the progress of the participants in mastering the literacy of their mother tongue, two types of tests were planned, namely a fluent read aloud test (RT) and a dictation tests (DT). The excerpts for the tests were selected from the first grade Persian language textbooks which are published by the Iranian Ministry of Education and are the compulsory textbooks for the first graders nationwide. The DT, which was designed to assess students' ability in making grapheme-phoneme association in Persian writing, consisted of 9 Persian sentences of 43 words. The same excerpt was used as the content of the second DT while to eliminate the impact of practice effect, the third DT had a different content from the first two and it included 5 Persian sentences of 34 words altogether.

As for the reading test, the first and the second reading excerpts were the same including 8 Persian sentences, of 39 words which were designed to assess the students'Persian reading skill. They were administered over two 16-week intervals to observe the progress of students in Persian literacy through the same text, but the excerpt for the third administration was different from the first two. It consisted of 6 Persian sentences, including 33 
words altogether and was administered $32^{\text {nd }}$ week after the outset of the study.

Three professional first grade teachers who were experts in teaching Persian literacy were consulted in order to confirm the content validity and the clarity of the chosen texts.

\subsection{Design}

The literacy skills of the young learners in monolingual and bilingual schools in this study were planned to be assessed in two phases: once in the middle of the school year (16 weeks after the starting point of literacy instruction), and once at the end of the academic year (32 weeks after the starting point). The Schematic representation of the study is presented in Figure 1.

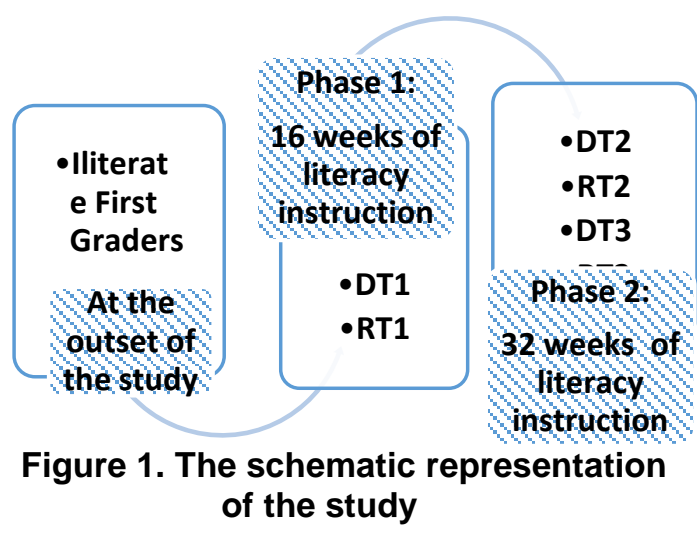

In the short term evaluation DT1 and RT1 were administered in both groups. In the second phase, the same contents were used as DT2 and RT2 i.e. the same tests were repeated after a period of 16 weeks to evaluate the rate of progress of the two groups. Moreover to see the impact of the type of content in our assessment, this stage was followed by the third evaluation procedure (RT3 and DT3) with different contents compared to the first and the second series of tests.

In the first and second phase of the study the teachers of both schools dictated the chosen texts to their students, but as for the reading test students were assessed individually by the researchers. Each student's reading was recorded for further analysis.

\section{Data Analysis}

The results obtained from the tests used in this study will be analyzed in two sections as follows:

\subsection{Dictation Test}

In scoring the dictation tests, this study followed the Iranian Ministry of Education guideline for the first grade dictation marking procedure i.e. for each misspelled word, the participants lost different points depending on the type of error. The final score was obtained by reducing the lost points of each student from 20 .
The total dictation score of each participant at each administration was computed through averaging the two sets of scores produced by two raters. Moreover, the Pearson-Product Movement analysis indicated a high inter-rater reliability in the scoring procedure ( $r>0.9$ for all three dictation tests).

The descriptive statistics of the results obtained through the dictation tests are presented in table 1.

Table 1. Descriptive statistics for dictation test scores of monolingual and bilingual groups

\begin{tabular}{|c|c|c|c|c|}
\hline & Students & Number & Mean & SD \\
\hline \multirow{2}{*}{ DT1 } & Bilinguals & 22 & 16.21 & 3.207 \\
\cline { 2 - 5 } & Monolinguals & 22 & 15.87 & 4.071 \\
\hline \multirow{2}{*}{ DT2 } & Bilinguals & 22 & 18.909 & 1.444 \\
\cline { 2 - 5 } & Monolinguals & 22 & 19.568 & .695 \\
\hline \multirow{2}{*}{ DT3 } & Bilinguals & 22 & 17.534 & 1.768 \\
\cline { 2 - 5 } & Monolinguals & 22 & 16.727 & 2.865 \\
\hline
\end{tabular}

In order to compare the results and to trace any existing significant difference, an independent samples t-test and two Mann-Whitney tests were used to compare the mean scores of the DTs of the two groups obtained in the first and second phase of the study.

The first statistical analysis (Leven's test) indicated that the two groups had equal variances on the first dictation test [(With F $(42)=2.743, P=$ 0.10 (two-tailed)]. Moreover, the comparison of mean scores through an Independent samples t-test revealed no significant difference between the two dictation mean scores of the bilingual and the monolingual groups in the first phase [With $\mathrm{t}(42)=$ 0.309, $P=0.759$ (two-tailed)]. This analysis indicated that there is no significant difference in the mastery of L1 literacy between the first graders in bilingual and monolingual first graders regarding their dictation accuracy in short term (after 16 weeks of literacy instruction).

As the assumption of normality was not observed in the distribution of DT2 and DT3 scores in any of the groups, a Mann-Whitney test was applied for each of the two tests to compare the mean scores. The observed $\mathrm{z}$ values of -1.549 and 0.814 on DT2 and DT3 did not equal or exceed the $\mathrm{z}$ critical value of 1.96 for a two-tailed test at the 0.05 level. Thus, interestingly similar to the first phase dictation analysis, the differences were not significant, and the two groups were not different in terms of their dictation accuracy in the second phase of the study i.e. after 32 weeks of literacy instruction. In other words, contrary to the objections made by some Persian literacy first grade teachers, simultaneous literacy teaching of L1 and L2 did not have a negative impact on the orthographic mastery of L1 in the bilingual school since the monolingual students did not outperform their counterparts in the bilingual school. 


\subsection{Reading Test}

In scoring the reading test, an analytic approach was utilized to evaluate both the accuracy and the fluency of learners. As for the accuracy, different scenarios which the students had undergone with different words in the reading process were listed (i.e. the word was read correctly, spelled and read correctly, spelled and read incorrectly, spelled and read incorrectly but self-corrected immediately, read incorrectly without being spelled, missed by the student but read correctly after the student was returned by the researcher, missed by the student and read incorrectly after the student was returned by the researcher and read incorrectly). Compared to the ideal situation in which the word was read correctly by the student without being spelled, each of the cases on the list were given different negative values. For example, if the word was spelled but read accurately the student was to lose 0.25 points, but if the word was spelled and finally misread, the student was supposed to lose 1 point. The number of each of the above mentioned occurrences was counted for each student, multiplied by the weight given to each and reduced from the total mark. The student who managed to read all the words accurately without either producing the phonemes separately, trying to connect them or skipping the words, was supposed to obtain the full mark for reading accuracy.

As for the fluency of reading, the total time each student spent on reading the text was used as the medium criterion. The shortest time obtained by the best reader who read the text with no pause was assigned as the standard time and medium of evaluation of other readers in each of the reading texts, and the fluency of each student was compared to the shortest duration by dividing the time spent by each student (in seconds) by the shortest time minus one (in this way, the best reader whose nominator and denominator in the fraction were the same did not lose any mark (e.g. $43 \mathrm{sec} / 43 \mathrm{sec}=1-1=0$ ). The total reading score of each participant at each administration was also computed through averaging the two sets of scores produced by the two raters.

Table 2 represents the detailed checklist used for rating the reading accuracy of the participants.

To analyze the reading ability of the participants, three different rating procedures were applied: a) considering the accuracy of the readers in their reading aloud without considering the time spent by each reader, b) considering the reading fluency of the learners by putting into account the time spent by each student and c) integrating both the time spent by each reader and the accuracy of reading altogether. Obviously, applying these three different procedures from three different standpoints (accuracy, fluency, integrating accuracy and fluency) led to different results the descriptive statistics of which are given in table 3 .
Table 2. The rating scale for the read aloud tests

\begin{tabular}{|l|l|l|}
\hline \multicolumn{2}{|c|}{ Type of Error } & weight \\
\hline 1 & Spelled \& read correctly & -0.25 \\
\hline 2 & $\begin{array}{l}\text { Read incorrectly, returned \& read } \\
\text { correctly }\end{array}$ & -0.25 \\
\hline 3 & $\begin{array}{l}\text { Missed the word, returned \& read } \\
\text { correctly }\end{array}$ & -0.25 \\
\hline 4 & $\begin{array}{l}\text { Spelled \& read incorrectly, quickly } \\
\text { corrected it }\end{array}$ & -0.5 \\
\hline 5 & $\begin{array}{l}\text { Missed the word, was returned \& read } \\
\text { correctly }\end{array}$ & -0.5 \\
\hline 6 & $\begin{array}{l}\text { Read incorrectly, was returned \& read } \\
\text { correctly }\end{array}$ & -0.5 \\
\hline 7 & $\begin{array}{l}\text { Spelled \& read incorrectly } \\
\text { (or corrected it with help) }\end{array}$ & -0.75 \\
\hline 8 & Just spelled the word & -0.75 \\
\hline 9 & Without spelling read incorrectly & -1 \\
\hline 10 & $\begin{array}{l}\text { Missed the word, returned \& read } \\
\text { incorrectly }\end{array}$ & -1.25 \\
\hline 11 & $\begin{array}{l}\text { Read the word incorrectly, was returned \& } \\
\text { again read it incorrectly }\end{array}$ & -1.5 \\
\hline
\end{tabular}

Table 3. Descriptive statistics for reading tests of monolingual and bilingual groups

\begin{tabular}{|c|c|c|c|c|}
\hline Tests & Measures & Students & Mean & SD \\
\hline \multirow{6}{*}{ RT1 } & \multirow{2}{*}{ RA1 } & Bilingual & 35.34 & 3.146 \\
\hline & & Monolingual & 33.69 & 3.740 \\
\hline & \multirow{2}{*}{ RF1 } & Bilingual & 2.41 & 1.525 \\
\hline & & Monolingual & 3.28 & 1.903 \\
\hline & \multirow{2}{*}{ RAF1 } & Bilingual & 32.92 & 4.582 \\
\hline & & Monolingual & 30.41 & 5.315 \\
\hline \multirow{6}{*}{ RT2 } & \multirow[t]{2}{*}{ RA2 } & Bilingual & 37.602 & 1.057 \\
\hline & & Monolingual & 36.801 & 1.574 \\
\hline & \multirow{2}{*}{ RF2 } & Bilingual & .686 & .466 \\
\hline & & Monolingual & 1.262 & .908 \\
\hline & \multirow{2}{*}{ RAF2 } & Bilingual & 36.915 & 1.486 \\
\hline & & Monolingual & 35.538 & 2.393 \\
\hline \multirow{6}{*}{ RT3 } & \multirow{2}{*}{ RA3 } & Bilingual & 31.136 & 1.442 \\
\hline & & Monolingual & 30.460 & 2.274 \\
\hline & \multirow{2}{*}{ RF3 } & Bilingual & 1.009 & .799 \\
\hline & & Monolingual & 1.684 & 1.674 \\
\hline & \multirow{2}{*}{ RAF3 } & Bilingual & 30.126 & 2.212 \\
\hline & & Monolingual & 28.775 & 3.808 \\
\hline
\end{tabular}

A series of independent samples t-tests and a Mann-Whitney testwere used again to see if there exists a significant difference between the marks obtained in reading assessment of the students (from three different perspectives of reading accuracy, reading fluency, integrated reading 
Table 4. Independent samples t-test results for comparing the Reading scores of the two groups in phase 1

\begin{tabular}{|c|c|c|c|c|c|}
\hline \multirow{2}{*}{} & \multicolumn{2}{|c|}{ Leven's Test } & \multicolumn{3}{|c|}{ T-Test } \\
\cline { 2 - 6 } & $\mathrm{F}$ & Sig. & $\mathrm{T}$ & $\mathrm{df}$ & $\begin{array}{c}\text { Sig. } \\
(2- \\
\text { tailed }\end{array}$ \\
\hline RA1 & 2.97 & .09 & 1.587 & 42 & .120 \\
\hline RF1 & 1.76 & .19 & -1.65 & 42 & .120 \\
\hline $\begin{array}{c}\text { RA1 } \\
\text { \& } \\
\text { RF1 }\end{array}$ & 1.73 & .19 & 1.681 & 42 & .100 \\
\hline
\end{tabular}

accuracy and fluency). Table 4 summarizes the results obtained.

As it is indicated in the above table, it was decided that the two groups had equal variances on RA1, RF1, and RAF1 tests, and that there were no statistically significant differences between the mean scores of the two groups in either of the entities measured i.e. reading accuracy, reading fluency and the integrated reading accuracy and fluency evaluation in the short term (16 weeks after the treatment) in the first phase of the study. Therefore, monolingual and bilingual first graders did not perform significantly different either on their dictation or on their read-aloud test in the short term. In other words, simultaneous teaching of L1 and L2 literacy did not have a negative impact on the literacy mastery of bilingual school first graders as compared to their counterparts in the monolingual school.

Nevertheless, the analysis of the data obtained in the second phase of the study lead to different results depending on the type of text used for evaluation.

The analysis of the second reading test (table 5) indicated that the two groups had unequal variances on RF2 and equal variances on RAF2 (With F (42) $=4.462, P=0.04$ (two-tailed) for RF2 and F (42) = 2.420, $P=0.12$ (two-tailed) for RAF2). Moreover from the t-test analysis of comparison of means it was concluded that there were statistically significant differences between bilingual and monolingual groups on RF2 and RAF2 [t (42) = 2.644, $\mathrm{P}=0.013$ (two-tailed) for RF2 and $\mathrm{t}(42)=$ 2.292, $\mathrm{P}=0.027$ (two-tailed) for RAF2]. Surprisingly this difference was not significant between the two groups when the results of the third reading test were analyzed $[\mathrm{t}(42)=1.177, \mathrm{P}=$ 0.246 (two-tailed) for RA3; $\mathrm{t}(42)=-1.706, \mathrm{P}=$ 0.098 (two-tailed) for RF3, and $\mathrm{t}(42)=1.439, \mathrm{P}=$ 0.158 (two-tailed) for RAF3].
Table 5. Independent samples t-test results for comparing the Reading scores of the two groups in phase 2

\begin{tabular}{|c|c|c|c|c|c|}
\hline \multirow{2}{*}{} & \multicolumn{2}{|c|}{$\begin{array}{c}\text { Leven's } \\
\text { Test }\end{array}$} & \multicolumn{3}{|c|}{ T-Test } \\
\cline { 2 - 6 } & $\mathrm{F}$ & $\mathrm{Sig}$ & $\mathrm{T}$ & $\mathrm{df}$ & $\begin{array}{c}\text { Sig. } \\
(2- \\
\text { tailed } \\
\text { ) }\end{array}$ \\
\hline RF2 & 4.46 & $\mathbf{. 0 4}$ & -2.64 & 42 & .011 \\
\hline RAF2 & 2.42 & .12 & 2.292 & 42 & $\mathbf{. 0 2 7}$ \\
\hline RA3 & 2.33 & .13 & 1.177 & 42 & .246 \\
& & & 1.177 & 35.54 & .247 \\
\hline RF3 & 3.88 & $\mathbf{. 0 5}$ & -1.70 & 42 & .095 \\
& & & -1.70 & 30.09 & .098 \\
\hline \multirow{2}{*}{ RAF3 } & 2.56 & .11 & 1.439 & 42 & .158 \\
& & & 1.439 & 33.72 & .159 \\
\hline
\end{tabular}

Moreover, since the assumption of normality was not observed in the distribution of RA2 scores in any of the groups, a Mann-Whitney test was applied for this test. As the observed $\mathrm{z}$ values of 1.86 on RA2 did not equal or exceed the $\mathrm{z}$ critical value of 1.96 for a two-tailed test at the 0.05 level, the differences were not significant, and the two groups were not different in terms of reading accuracy (seen text) in the long term or in the second phase of the study.

In sum, after 16 weeks of literacy instruction, there was no significant difference observed in the L1 reading mastery of monolingual and bilingual school students whether considering their accuracy, their speed (fluency) of reading or considering both the accuracy and the fluency. But, after 32 weeks of literacy instruction (in phase 2 of the analysis), bilinguals outperformed their monolingual counterparts in terms of their reading fluency and also integrated reading accuracy and fluency scores.

\section{Results and Discussion}

As mentioned in the data analysis, in the short term of 16 weeks after the starting point of literacy instruction, the first grade participants from two bilingual and monolingual schools in Tehran did not differ significantly neither in encoding (evaluated through a dictation test) nor in decoding (assessed through reading test) the orthographic symbols of their mother tongue (Persian). Since the dictation and reading skills of the young learners 
was assessed as a means of literacy, the short term results of the study indicated that bilingual education has no statistically significant effect on young learners' Persian literacy at first grade primary schools, in the short term. However, in the second phase of the study (in the long term of 32 weeks after the starting point of literacy instruction), there were significant differences between the fluency and also integrated accuracy \& fluency of the reading of bilingual and monolingual school first graders. In other words, Bilingual school first graders outperformed their monolingual counterparts after 32 weeks of simultaneous literacy instruction in L1 and L2 in their reading fluency and also integrated accuracy \& fluency of the second reading test.

One important issue in investigating the literacy of young learners which sheds light to the reliability and comparability of the results obtained from different studies is the way the reading aloud skill (decoding the orthographic symbol and making the grapheme-phoneme association) is evaluated and scored. The problem is that there has been no consistent way used by the researchers in this area in scoring and rating the fluency and accuracy of the learners reading. This may account for the different results obtained. For instance in this study a specific checklist was prepared which included different scenarios which were likely to happen in reading a word. Based on a comparison made between each instance on the list to the ideal situation in which the learner reads a word without spelling, sound producing, hesitating or skipping it, the occurrence of each instance was recorded, counted and involved in scoring the students. Moreover, the time spent by each learner was traced and considered as a medium to measure the reading skill of learners. It seems that this rating procedure was not what other scholars operationalized in their evaluation. Consequently the results of similar investigations should be compared cautiously.

The Persian first grade teachers who make complaints regarding the simultaneous teaching of L1 and L2 literacy, usually justify their stand point by providing documentary samples of their students dictations in Persian in which the young learners confuse the L1 and L2 graphemes, and this will lead sometimes to the appearance of some words in the Persian scripts of the learners with embedded English letters. In fact there is ample evidence of the writing samples of the bilingual school first graders which clearly manifests the challenge biliteral learners in bilingual schools face. This challenge is clearly due to two main reasons. First, although both English and Persian have alphabetic writing systems, the two languages have totally different graphemes. Second, the direction of the writing process is different in two languages i.e. Persian writing system is a right to left one.
Given the results obtained in the first phase of the study (which is the same period that usually teachers report mingled written words), we argue that since we did not observe any significant difference in the rate of literacy gained by monolingual and bilingual school students, even in case of the occurrence of these phenomena of confused mingled words, mirror or wrong direction writing, they should not be accounted as serious problematic occurrences. Consequently the mingled confused words can be assumed as rare occurrences which will not last long and will not have a significant role in the mastery of the literacy skill.

In sum, the results of this study can be considered as an evidence for the truth-value of the claim made by Escamilla [19] that contrary to current debates on language policy, young children learning two languages develop and use vocabulary and phrases at the same rate as children learning only one language.

Moreover, the variable of the type of the text used in the reading test appeared to be an identifying factor in the results obtained. As it was mentioned before, the comparison of the mean scores of RT2 of the two groups indicated a significant statistical difference between the groups. But the same analysis on RT3 (which had a different content compared to RT1 and RT2) showed no significant difference between the groups. Considering the fact that RT2 and RT3 were administered in two subsequent days of the 32 nd week of the school year and students were in the same level of literacy mastery, it is concluded that the type of the text used in the reading test may be an identifying factor in the results obtained.

In fact the literacy instruction in Persian starts with cases in which there is one to one correspondence of a phoneme with a grapheme which obviously is easier to be grasped by young learners. From the 20th week of the academic year, teachers gradually move to more difficult cases that there is more than one representation for a phoneme which is more complex cognitively and appears to be more difficult to be mastered by the young learners. The different results obtained in the second and third reading tests may be due to the level of difficulty of content of these tests.

Like all other studies in the field, this study had a number of limitations which should be considered in interpretation of the results. Participants were from two bilingual schools and from 4 different classes with different teachers. In fact the effect and effectiveness of teacher variable was not considered in this study. Moreover, no randomization was involved in the selection of the participants in the bilingual group, but the participants in the monolingual group were selected randomly, since they outnumbered the bilingual ones. 


\section{Conclusions}

This study investigated the impact of simultaneous literacy instruction of L1 and L2 in the L1 literacy learning of first graders in a bilingual school. To this end, the fluency and accuracy of the L1 literacy learning of a group of first graders in a bilingual school were compared to their counterparts in a monolingual school in two short and long term phases i.e. 16 weeks and 32 weeks after the starting point of the instruction. The comparison of the results obtained in the first phase indicated no significant difference in the L1 literacy rate of the monolingual and bilingual school students in short term, neither in their dictation accuracy nor in the fluency and accuracy of L1 reading aloud. This finding is in line with what Kovelman et al. [20] hold that "Young children can learn two reading systems and two languages concurrently and without confusion, especially if such dual reading and language exposure occurs early in life". The results in long term investigation were not exactly the same. After 32 weeks of literacy instruction, in the second phase of the study, the students were asked to sit for the same dictation and reading tests with the same context as the phase 1 . Moreover in order to eliminate the probable impact of the seen text as an influential factor in the results, we planned to have an unseen dictation and reading test as well. The same data analysis procedure of the first phase was applied to compare the mean scores of the two groups in different variables (dictation accuracy, reading accuracy, reading fluency, integrated accuracy and fluency). Interestingly, this comparison indicated that there is a significant difference between the fluency and also integrated accuracy and fluency of the reading ability of bilingual and monolingual school first graders. In other words, Bilingual school first graders outperformed their counterparts after 32 weeks of simultaneous literacy instruction in L1 and L2 in their reading fluency.

We conclude that there is no difference in the L1dictation accuracy, reading fluency and reading accuracy of first graders in bilingual and monolingual schools in short term, though in long term the bilinguals will be better readers in their L1 as far as fluent reading and speed of reading is considered and they will be like their counterparts in the monolingual schools in dictation test. In short the simultaneous teaching of L1 and L2 is an opportunity rather than a threat for first graders.

\section{References}

[1] Barac, R., Bialystok, E. Cognitive development of bilingual children. Language Teaching, 2011, 44, 36-54.

[2] Bialystok, E., G. Luk, K. F. Peets\& S. Yang. Receptive vocabulary differences in monolingual and bilingual children. Bilingualism: Language and Cognition, 2010.
[3] Menken, K. Emergent bilingual students in secondary school: Along the academic language and literacy continuum. Language Teaching, 2013, 46, pp 438-476.

[4] Woolfolk, A. Educational Psychology, 8th ed. Allyn and Bacon, Needham, MA, 2001.

[5] Caldas, S. J. Raising Bilingual-Biliterate Children in Monolingual Cultures. MULTILINGUAL MATTERS LTD. 2006.

[6] Bialystok, E. Bilingualism in development: Language, Literacy, and Cognition. New York: Cambridge University Press, 2003.

[7] Diaz, R. Thought and two languages: The impact of bilingualism on cognitive development. In E.W. Gordon (Ed.) Review of Research in Education, lo, 23-54. Washington D.C.: American Educational Research Association. 1983.

[8] Cameron, L. Teaching Languages to Young Learners. New York: Cambridge University Press, 2001.

[9] Hamers, J. F., \& Blanc, M. H. A. Bilinguality and Bilingualism (2nd ed.). United Kingdom: Cambridge University Press, 2000.

[10] Christie, F. Language Education in the Primary Years. Australia: UNSW Press, 2005.

[11] Gudschinsky, S. Mother-tongue literacy and second language learning. In W. F. Mackey and T. Andersson (Eds.), Bilingualism in early childhood. (pp. 250-258). Rowley, MA: Newbury House Publishers. 1977.

[12] Ramírez, D. J. (2000). Bilingualism and Literacy: Problem or Opportunity? A Synthesis of Reading Research on Bilingual Students. A Research Symposium on High Standards in Reading for Students from Diverse Language Groups: Research, Practice \& Policy.

[13] Tsai, Y. R., Ernst, C., \& Talley, P. C. L1 and L2 strategy use in reading comprehension of Chinese EFL readers. Reading Psychology, 31(1), 2010. 1-29.

[14] Hussien, A. M., The Effect of Learning English (L2) on Learning of Arabic Literacy (L1) in the Primary School. International Education Studies, 2014, 7 (3).

[15] Berens, M. S., Kovelman, I., \&Petitto, L. Should Bilingual Children Learn Reading in Two Languages at the Same Time or in Sequence? Bilingual Research Journal: The Journal of the National Association, 2013.

[16] AL dohon, H. I. M. The Effect of Second-Language Learning on Elementary EFL Learners' Literacy Skills. International Journal of Education and Research, 2014.

[17] Marsh, H.W. Late immersion and language of instruction in Hong Kong High schools: Achievement growth in language and non-language subjects. Harvard Educational Review, 2000, 70 (3), 303-346.

[18] Verhoeven, L. T. Transfer in bilingual development: The linguistic interdependence hypothesis revised. Language Learning, 44, 1994. 381-415.

[19] Escamilla. K. Teaching Literacy in Spanish, In R. DeVillar\& J. Tinajero (eds). The Power of Two 
Languages 2000, New York, McMillan/McGraw-Hill, 1999. $126-141$.

[20] Kovelman, I., Shalinsky, M. H., Berens, M. S., \& Petitto, L. A. Shining new light on the brain's "bilingual signature": A functional near infrared spectroscopy investigation of semantic processing.Neuroimage, 39, 2008. 1457-1471 